\title{
Transforming the Narrative of the History of Chinese Technology: East and West in Bertrand Gille's Histoire des Techniques
}

\author{
Yao Dazhi \\ Institute for the History of Natural Science, CAS \\ 55 Zhongguancun East Road, Haidian, \\ Beijing 100190, China \\ E-mail: yaodz@ihns.ac.cn
}

\section{Per Högselius}

Division of History of Science, Technology and Environment, KTH Royal Institute of Technology

Teknikringen 74D, Stockholm SE-100 44, Sweden

E-mail: perho@kth.se

\begin{abstract}
In his magisterial The History of Techniques, the French historian of technology Bertrand Gille (1920-1980) constructs a Western-centric world history of technology based on a technical systems approach. In doing so, he is forced to deal with the tension between Western-centric approaches and the conventional narrative of the history of Chinese technology. In order to avoid internal contradictions within his world history framework, Gille reconfigures the historical narrative about ancient China's great inventions, arguing against unidirectional technology transfer and introducing the alternative notions of technological concomitant evolution and technological exchange. While Gille integrates ancient China into the general technological development of the world, he treats China as a blocked technical system and as "the other" in the West's technological self-perception.
\end{abstract}

Keywords: ancient China, Bertrand Gille, blocked civilization, East-West relations, historical narrative, The History of Techniques 
Yao Dazhi

Per Högselius

\section{Introduction}

One of the main challenges for scholars seeking to grasp the history of technology in its global context is to harmonize the relationship between narratives of Chinese history and of Western history. Most Western accounts of the history of technology have tended to adopt a Western-centric perspective, using the Western path of development as the most important reference frame. The Western development has usually been regarded as a success story, and when non-Western societies have been analyzed a common research question has been why these were not able to develop as successfully as the West. Most Chinese accounts, in contrast, adopt a China-centered perspective in which the main emphasis is not necessarily on the modern period, during which Western technology undoubtedly developed at a spectacular pace, but rather on earlier periods in history, during which China, according to these authors, was at the forefront in global technological development. This perspective has also been supported by China-oriented Western historians of science and technology, starting with Joseph Needham's pioneering work.

How, then, can Western- and Chinese-centric perspectives of the history of technology be harmonized? Many historians have found it formidably difficult to unite Chinese and Western perspectives. The Chinese historian of science Wu Guosheng (吴国盛) has argued that “many approaches to embedding [Chinese history into a world history] usually are readily unnatural... [and they do not seem like] a whole and single history, but two completely different historical narratives that are simply pieced together" (Wu, 2009, p. 179).

In this article we study the tensions between Western- and China-centered narratives in the history of technology. We argue that the analysis of such tensions constitutes an important task for historians of science and technology. Especially for scholars with ambitions to construct a transnational or global history of science and technology, it is essential to reveal the nature of the tensions and conflicts between Western- and Eastern-centered narratives. However, it is often difficult to reveal the conflicts and their causes in practice, because explicit tensions between conflicting narratives are usually erased from the texts. This article nevertheless tries to do precisely this, exposing one particular case: the French historian of technology Bertrand Gille's (1920-1980) attempt to transform the historical narrative about the Far East and thereby solve the problem of the tension between two types of narratives. 
In his Histoire des Techniques, Gille $(1978 ; 1986 a)$ was aware of the need to resolve the apparent contradiction between a brilliant image of ancient China and the Western-centered framework of world history. There seem to be two principal ways of doing this: one is to abandon the Western-centric framework, the other is to transform the very core of the narrative of the history of ancient China's technology. Gille followed the second strategy. In order to reconstruct the process in which he transformed the narrative of China's technological development, let us first examine the tension between the dominant narratives of China and of the West.

\section{The conflict between the conventional narrative of the history of technology in ancient China and the framework of a world history of technology}

\section{The Western-centric framework of history of technology}

Gille criticizes conventional approaches to the history of technology and introduces the alternative approach of technical systems analysis. From his point of view, historians of technology have focused too much on isolated technologies. This attitude, he writes, often made history of technology a collection of inventions and inventors' biographies (Gille, 1986a, pp. ix-x). Gille believes that a technology, even a primitive tool, is usually compound. And in a more complex layer, any single technology is always linked to other technologies. These interconnected technological elements can be understood in the context of technology as a system. It is only in a system that a tool or machine can become a technical element and obtain its own value as something technical. This approach also implies that there is an interaction between technical systems and other social and cultural systems, and makes possible a dialogue between historians of technology and experts of other disciplines, such as economy, philosophy, sociology, and political science.

Based on the notion of the technical system, Gille tries to construct a world history framework. In fact, he was not the only historian of technology who experimented with a systems approach at the time. The American historian of technology Thomas P. Hughes, for example, developed his "large technological systems" theory at about the same time (Hughes, 1983; 2012). Hughes's methodology has had an overwhelming influence on the Anglo-Saxon academic 
community. Gille's approach differs from Hughes's in some respects (Picon, 1998, pp. 37-39; Fox, 1998, pp. 4-5). Though Gille, similarly to Hughes, emphasizes interactions between technical and other social systems, he does not define the technical system in relation to social, economic, and political systems, preferring, instead, to abstract it out of human society in long historical periods. He claims that if one can work with an appropriate language, and also with models based on precise concepts, technology can be analyzed on a global level (Gille, 1986a, p. 9). He also believes that history can be assessed in terms of a series of successive technical systems (Gille, 1986a, p. 17).

In The History of Techniques, human history is divided into several long periods. Each period is dominated by a certain technical system, and technologies evolve by virtue of the successive replacement of technical systems. A technological revolution is a mutation or replacement of technical systems in concrete social environments. Gille identifies a series of technological revolutions in human history. The earliest is the medieval technological revolution that occurred in the $12^{\text {th }}$ and $13^{\text {th }}$ centuries (Gille, 1986a, p. 441). The next took place in the second half of the $15^{\text {th }}$ century, coinciding with the European Renaissance (Gille, 1956, p. 651). In the $18^{\text {th }}$ century, the Industrial Revolution transformed the system that had been dominant since the Renaissance, and technical progress and population growth reappeared. In addition to the medieval revolution, the Renaissance revolution and the Industrial Revolution, Gille identifies a further technological revolution in the second half of the $19^{\text {th }}$ century and another one leading up to the contemporary technical system.

Gille's world history of technology has an essence of Western centrism. Generally speaking, in the works of world history based on Western centrism, the progress of Europe forms a reference frame against which other civilizations are measured and evaluated. In The History of Techniques, the Western civilization is the only one that went through all technological revolutions. From this perspective, Gille's global narrative may be regarded as a typical example of Western-centered historical narratives.

In order to understand the potential conflict between Gille's narrative and the China-centered ones, the China-centered narrative should be examined next. 
The conventional narrative of history of technology based on Chinese centrism

The achievements of Needham have strongly influenced the history of science and technology in China. Gille's account of the history of technology in ancient China also draws heavily on Needham's works (Gille, 1986b, pp. 1202-1203). What are the presuppositions of the established, conventional narrative of history of technology in China?

The conventional view of Chinese technology, as reflected in Needham's works (Needham, 1945; 1981; 2005) and in the works of contemporary Chinese historians of technology, is based on Chinese centrism. A typical example is the formulation by Pan Jixing (潘吉星) of the Chinese Academy of Science's Institute for the History of Natural Sciences:

Science and technology in ancient China was advanced all the while. More than half of all elementary discoveries and inventions on which the rise of the modern world depends originated in China, and at least more than one hundred fundamental discoveries and inventions had an influence on world science and technology. In this sense, China kept a leading position in the field of technology throughout the long medieval period. Papermaking, printing, gunpowder, and the compass were earthshaking and revolutionary great inventions in the last two-thousand years, as far as their impact on the course of social history and scientific and cultural development is concerned. (Pan, 2002, p. 1)

Based on the above quotation, three points can be made. First, a series of great Chinese inventions had a real influence on the world, particularly on the Western world. Second, these inventions demonstrate that Chinese technologies were more advanced than those of the West in pre-modern times. In other words, there is a close relation between specific inventions and the overall development of technology in a region. The fact that a number of important inventions originated in China entails Chinese advance over the West before modern times.

Third, to a certain extent the overall advancement of ancient Chinese technology was demonstrated by virtue of unidirectional technology transfer. Technology transfer, as an analytical concept, primarily refers to a process by which a technology invented in one country or region is transplanted or conveyed to another country or region. That the rise of the modern Western world depended on Chinese inventions implies that those inventions were transferred from China to the West. The precondition for technology transfer to be meaningful is that 
there is a technical difference or disequilibrium between two regions. As one contemporary Chinese historian of technology puts it, if there is one country where a certain technology is employed and another where the same technology is not employed, or only a lower-level technology is used, technology transfer can take place (Zhang, 2004, p. 2). In this sense the transfer of a number of technologies also demonstrates technical disequilibrium between different regions. The transfer of the "four great" Chinese inventions is especially significant, for they are of great symbolic value and are commonly referred to when assessing the relative level of technical development in China and the West.

Thus, three arguments form the basis of the conventional narrative of ancient China's history of technology: (1) A series of important technologies were invented in ancient China, (2) these technologies were transferred to the West, and (3) ancient China's technological level was higher than that of the West. These China-centered presuppositions are closely interlinked. On their basis, the conventional narrative of the history of Chinese technology is constructed. In this narrative, technical progress took place when and where new technologies were invented. More specifically, inventions, especially the four "great" ones, marked the advance of Chinese technology and society. Furthermore, technical progress is continuous by virtue of the accumulation of individual inventions. Finally, individual technologies themselves are elementary metaphysical objects in the history of technology. These closely connected arguments form a relatively complete construct. It provides a brilliant image of ancient Chinese technical civilization, and conforms to principles of the conventional historical view. Gille had to absorb into his world history this theoretical construction.

The conflict between narratives of China-centered and Europe-centered world history

Chinese historians and Western historians of Chinese science and technology, such as Needham, generally emphasize that China played an important role in ancient times. In their eyes, ancient China was technologically advanced. Technological advancement, however, cannot be understood without the related notion of backwardness. It is by a reference frame or by comparison with other parts of the world that we can evaluate the technological level of a region. If we accept the China-centric narrative by admitting that there were a number of advanced technologies in ancient China and that these technologies were transferred to the West, it seems reasonable to conclude that Western technology in pre-modern times was not more advanced than that of China, and that it probably lagged behind the latter. This perspective is consistent with 
earlier ideas about Europe's "dark ages", which supposedly were characterized by intellectual darkness, social and economic regress, and technical stagnation before the Renaissance. The high level of Chinese technology seems to suggest that European technology in the Middle Ages was relatively backward.

However, Gille's notion of global evolution of technical systems suggests that civilizations in the same period generally shared the same system, except in some special cases. Analyzing the medieval and Renaissance technological revolutions, he rejects the notion of backwardness of European technical development in the pre-modern period, and regards its evolution as a standard course of global technical evolution, or even as an interpretative framework. This is not consistent with the conventional narrative of ancient China's technology. If European technology evolved successfully, it could not lag behind other technical regions, including China. Hence the ancient Chinese technical level could not be relatively advanced.

It is thus necessary to reconstruct the conventional narrative of the history of China's technology. Gille notes that for Needham and other historians, Chinese technologies seem to have begun to advance over their Western counterparts about two thousand years ago. However, he takes a critical stance to this perspective. For the sake of the perfection of his global framework, he denies that the technological level of ancient China was higher than that of the West. Yet the narrative of specific historical facts— such as those regarding the four great Chinese inventions-must, of course, also be taken into account as part of the overall technical system. When Gille begins to argue against the Chinese advancement, he sets about challenging these facts. In doing so, he reconstructs the conventional narrative of the history of technology in China. 


\section{Criticism and reconfiguration of the conventional narrative of the history of Chinese technology}

Based on his own historical framework, Gille reconfigures the historical narratives about Chinese inventions, arguing against conventional notions in the history of technology in China and introducing alternative notions in order to avoid internal contradictions within his world history framework.

Reinterpreting facts concerning China's great inventions

The four great inventions mentioned above undoubtedly occupy an important position in the conventional China-centered narrative. To a certain extent, Gille does recognize "the advance of the Chinese techniques over Western methods" (Gille, 1986a, p. 401) and the ingenuity of "the great inventions, those which marked China's advance over the West, such as printing, gunpowder, and the compass" (Gille, 1986a, p. 404). At the same time, however, he argues that the object of study in technological history should not be isolated technologies or artifacts, but technical systems. Based on that, he criticizes the dominant historical narrative.

In the case of printing, Gille denies that it originated in East Asia. He declares that the movable types that were invented by Pi Cheng (毕昇, 990-1051), along with related technological elements, had some defects, such as insufficient hardness, low paper quality, the absence of a press, and the unsuitability of Chinese ink. Because there were no other suitable technological elements to match Pi's movable types, it is difficult to regard the invention as a successful technical complex. The invention does not seem to have been absorbed into the technical system, and it was quickly forgotten after Pi's death. And then, Gille declares, "true printing was really invented in Europe around the middle of the $15^{\text {th }}$ century". (Gille, 1986a, p. 397) The invention should be attributed to Gutenberg, and the Far East does not seem to have had any influence whatsoever on it.

In the case of the compass, Gille claims, it "only became an important instrument with the development of navigation techniques and the crossing of the Atlantic" (Gille, 1986a, p. 404). He admits that human knowledge of the existence of magnets may well date from the $3^{\text {rd }}$ century $\mathrm{BC}$, and the earliest use of the compass in navigation may have occurred in the $12^{\text {th }}$ century. But it became a significant technique only when it was used for navigation on the whole coast. On 
several occasions, Gille seems reluctant to call the Chinese invention a compass, referring to it simply as a "south-point needle". The south-point needle and the compass may have worked on the same principle and shared similar mechanisms, but from Gille's point of view they had different values in the technical system, so they should be regarded as two different technical objects. (Gille, 1986a)

As for the invention of gunpowder, Gille believes that although the Chinese invented a mixture similar to it from the $1^{\text {st }}$ century, it is not necessary to identify it with that important object of military technological history. He emphasizes that "gunpowder was introduced with the development of sizeable artillery, which presupposes hundreds of other techniques". (Gille, 1986a, p. 404) Gunpowder gained its important position in the technical system mainly because of its extensive military use. Gille (1986a, p. 479) writes that it is quite likely that gunpowder was discovered accidentally in the European Middle Ages. The Chinese probably were the first to use sulfur and to color fires with the aid of metal oxides, but the substance does not seem to have been used for "fire-arms", but only for the creation of the world's first fireworks.

Gille was not the first scholar to question ancient China's technological achievements. But his arguments are unusually consistent and rigorous, based on intricate reflections on historical methodology.

Against unidirectional technology transfer: concomitant technological evolution and technological interchange

There are two important notions in Gille's own historical narrative of ancient China. One is the concomitant technological evolution of China and the West, and the other is the technological interchange between them. The notion of concomitant evolution refers to the tendency for technological improvements to be made in different geographical zones almost at the same time. Gille declares: "We have been able to note concordance in many fields between WestEuropean and Chinese technical development" (Gille, 1986a, p. 401). The notion of technological interchange emphasizes the significance of bidirectional communication. Gille writes, on the one hand, that "[p]erhaps the contribution made by China to a Western world [...] has been over-emphasized" (Gille, 1986a, p. 382), and on the other hand, that "the practice of borrowing Western techniques by China has not been emphasized enough" (Gille, 1986a, p. 401). With the help of these two notions, he argues that technical acquisitions could have taken place at the same time in different civilizations that were at a similar technical stage but were located far away from each other. What is the mechanism 
Yao Dazhi

Per Högselius

of this phenomenon? Gille thinks that in the evolution of global technical systems, inventions could be acquired concomitantly in different zones.

The notions of concomitant evolution and interchange allow Gille to reject the hypothesis of unidirectional technology transfer from China to the West, and they help to explain why there was no wide gap, in terms of technical development, between the two zones that are so far away from each other. Gille is cautious in his analysis of cases of technology diffusion from East to West (Gille, 1962; Hilaire-Pérez \& Verna, 2006, p. 542). In The History of Techniques, technology transfer from China to the West should not mainly be understood as individual cases, but rather as a general historical phenomenon. Technological concomitant evolution means that techniques evolved more or less independently in each region. China and the West had a reciprocal influence, but it was not so extensive in range and amount (Gille, 1986a, p. 402). In the China-centered history of technology narrative, unidirectional technology transfer and a series of important inventions originating in China allow us to infer the advanced level of technology in ancient China. If both notions of concomitant evolution and exchange replace the notion of unidirectional technology transfer, the argument that Chinese techniques were advanced is no longer valid. Undoubtedly, the two alternative notions are useful to test Gille's hypothesis that China and Western Europe shared common technical systems before the $15^{\text {th }}$ century.

Against the advancement of ancient China: parallel developments

Gille combines the notions of concomitant evolution and interchange to argue against long-term Chinese technological advance over the West. During the Neolithic period, China and Western Europe were at the same stage of technological development. Chinese developments occurred later than those in Mesopotamia and Egypt, and were contemporary with those in the eastern Mediterranean region. A conventional viewpoint holds out that Chinese technical developments seemed to be more advanced than those of Europe's classic civilizations. Gille claims that this is not true.

Gille defends his stance in several ways. First of all, now that there is a total lack of chronological tables about Chinese inventions, it is insurmountably difficult to evaluate the take-off of Chinese technological progress (Gille, 1986a, p. 381; 1986b, p. 1319). Gille notes that one authority (probably Needham, although his name is not mentioned) attributed one technology to periods which were separated by several centuries (Gille, 1986a, pp. 380-381). In order to assess 
the technological advancement of a civilization, he writes, we have to make sure when were those most important techniques invented there. However, the chronology of Chinese technologies is to some extent uncertain. This allows Gille to argue that it is difficult to infer that ancient Chinese technology was more advanced than that of the West.

Secondly, even if a number of important techniques originated from ancient China, that does not necessarily imply Chinese advance over Europe. Many Chinese inventions do not appear to have had any significant impact on Chinese society. They appear to have had a great influence only over the Western world. Only when technologies can be incorporated into the global technical system do they have their own significance or value. The so-called "leading" or "the latest" technology cannot be introduced into the system if a certain coherence does not exist between those technologies (Gille, 1986a, p. 404). The seemingly insignificant impact of many Chinese inventions on Chinese society implies that the technical system at that time was not advanced.

Thirdly, there were leading techniques in the West. Gille declares: "Metallurgy, glass making and ceramics all originated from Western techniques" (Gille, 1986a, p. 401), and "if we look at the mid- $13^{\text {th }}$ century, we would notice a brilliant technical civilization: should this exclude the remarkable cathedrals, irrigation systems of Spain, and the Scandinavian ships which crossed the Atlantic?" (Gille, 1986a, p. 382) Pointing to these technological achievements, Gille considers it implausible that ancient China's technologies were more advanced than those of the West for a long period.

According to Gille, Chinese technological literature showed that Chinese and Western technologies were almost at the same stage. He emphasizes that there are no satisfying records or exact chronology of Chinese techniques. But, as far as the extent of such technical literatures is concerned, Chinese technological development does not "appear to differ radically from what we have seen in Greece and Rome, or elsewhere in the Middle Ages in Europe" (Gille, 1986a, p. 384). Furthermore, it is not difficult for Gille to find cases in Chinese history to confirm his own hypothesis. According to certain records, the construction of the first water mill in China has been dated to $30 \mathrm{BC}$. It would have been just contemporary with the introduction of the Western mill. And it seems that the Western technologies concerning measurement of time and distances were not behind those of the East. The water clock was developed in the two areas at nearly the same time, and the appearance of it in the West may be somewhat earlier. By virtue of various methods and approaches, Gille argues that the overall 
developments of Western Europe seem not to be behind the East from the early period of human society to the $15^{\text {th }}$ century.

Gille hoped to make ancient Chinese history an integral part of a global history of technology. In order to harmonize the relationship between both historical narratives, he criticized historical facts and reshaped theoretical propositions. $\mathrm{He}$ challenged the narrations of China's great inventions, substituted his own notions of technological concomitant evolution and exchange for the conventional concept of unidirectional technology transfer, and introduced the notion of parallel development. It is obvious that what Gille would like to argue against are the primary presuppositions of China-centered narratives of technological history.

\section{"The other" in the image of global technological development}

There is another question that Gille had to respond to when transforming the conventional China-centered narrative. While he absorbed ancient China into the general course of global technological development, he tried to make Chinese technological civilization "the other".

\section{Blocked civilization: the Gille problem}

Western civilization shows its superiority in many fields from the $15^{\text {th }}$ century onwards, and the technological development of non-Western civilizations should be regarded as an experience of failure. Gille employs the notion of "blocked system" to generalize such failure (Bray, 2009, p. 30; 2002, pp. 160-162; 1998, p. 14).

According to the conventional historical narrative of ancient China, Chinese technological development slowed down from a certain point of time. Needham agrees that, on the one hand, Chinese science and technology were advanced compared to other parts of the world, and on the other hand, Chinese scientific thinking stagnated during a time when the West began to develop modern science. He asks why the Scientific Revolution did not happen in China. And just like Chinese science stagnated, Chinese technology was eventually surpassed by that of the West. Gille accepts the argument about China's stagnation. $\mathrm{He}$ emphasizes that the development of Chinese technologies was suddenly blocked in the $15^{\text {th }}$ and $16^{\text {th }}$ centuries, remarking that the relatively recent discovery of the 
fact that China remained fixed within an outdated technical system has to some extent discredited the Far East (Gille, 1986a, p. 381).

China thus becomes a prime case of what Gille calls a "blocked" technical system. The blockage of technical systems is a fundamental phenomenon in Gille's theory of technical evolution. All technologies are interdependent in a technical system, and if one of them reaches its limits and relevant technologies cannot be adjusted, the whole system will be blocked. The phenomenon usually becomes apparent at the end of the expansion of a system. The overcoming of such limits will lead to the further evolution of the technical system or to the emergence of a new system. Gille argues that the conventional historical narrative is problematic because it just focuses on successful inventions. Failures and limitations of technologies, he stresses, are also important and need to be taken into account. Based on the concept of the technical system, failed technical elements and blocked systems are proper research objects. The French historian of technology Bruno Jacomy (1990, p. 15) points out that when Gille discusses the blockage of systems, ancient China is pointed to as a typical case. While the Needham question mainly concentrates on the development of Chinese science, Gille abstracts his own question from the history of technology. Thus, Gille asks why ancient Chinese technical development was blocked.

Gille identifies a number of factors that may help to explain the blockage of technical systems. Blockages, he writes, may, on the one hand, be caused by internal factors, that is, they may arise from the limits of technical elements. Gille (1986a, p. 404) suggests that the delay or slow progress of other technical structures will naturally block the introduction of more advanced inventions. This means that certain established technical structures or elements could block the system's evolution, even if the progress of other aspects is obvious. On the other hand, external factors are also important. Interactions between a technical system and other social, economic, and scientific systems have an influence over technical change. For example, Gille emphasizes that the appearance of neoConfucianism was "capable of resolving all nature of problems, scientific and technical, as well as economic, political and social questions," and "certainly contributed to the stagnation of the Chinese technical system" (Gille, 1986a, pp. 404-406). Moreover, a bureaucratic feudalism played an important role in blocking the system. The Chinese policy of isolating itself from the outside world made it difficult for Chinese technological development to profit from outside contributions. Just like the Needham problem, Gille's problem in the history of technology has various answers. 


\section{"The other" in Western technical civilization}

The blockage of technical systems can explain why technical evolution slows down, or even falls into stagnation. Gille mentions systems of many civilizations that have been blocked, such as the blockage of the ancient Egyptian and the ancient Greek technical systems, and even that of the prehistoric era. He also lists pre-Columbian American empires and the Islamic world as blocked systems (Gille, 1986a, p. 380). However, it seems that these blockages are different from the blockage of China. But what, precisely, does the blockage of a technical system mean? Does it mean that a technical system could not evolve any further after a certain point in time, or does it rather imply that a civilization has been in a certain technological stage during a very long period of time?

Gille seems to prefer the former perspective, although for the case of the prehistoric era the latter one seems to fit better. As we have seen, however, Gille emphasizes that there is no exact chronology of Chinese technological development, making it hard to argue that technologies changed over time in ancient China. For the same reason, Gille had not enough evidence to prove that technical structures or elements reached their limit and blocked the further evolution of China's technical system. Gille also ignored the possibility of a technical revolution in ancient China. According to his notion of parallel development between China and the West before the $15^{\text {th }}$ century, the technical revolution that happened in Europe in the late Middle Ages should be mirrored by a similar revolution in China. But he seems to neglect this possibility. It is likely that Gille draws his conclusion concerning the blockage without sufficient evidence.

Despite the insufficiency of Gille's arguments, his concept of blockage remains of great interest. The technical evolution of Western Europe and the blockage of technical systems elsewhere in the world are two sides of the same coin. One of Gille's aims in The History of Techniques is to establish a Western-centric framework of global technical evolution. The global technical evolution implies a series of technical revolutions taking place in the Western world since the $12^{\text {th }}$ century, and technical systems of non-Western civilizations, including China, being blocked from a certain time on. In this Western-centered framework, nonWestern civilizations become "the others." 


\section{The invisibility of the conventional narrative of China's technological development}

In order to embed the Far East into his framework of global technical evolution, Gille constructs a new narrative of China's technological past. He reevaluates the overall position of ancient Chinese technological development, challenges the great Chinese inventions, and contests unidirectional technology transfer. As a result, ancient Chinese technology seems not to be more advanced than that of the West from the beginning of the Christian era to the $15^{\text {th }}$ century. Moreover, the stagnation of Chinese technological development stands out very well. Having abandoned the earlier notions and reshaped important historical facts, Gille reduces the technological advancement of ancient China to an illusion.

Consequently, the original historical narrative is to a great extent erased from Gille's text. In The History of Techniques, the general framework of global technical evolution is derived from the course of successive replacement of European technical systems, and those narratives which are not consistent with this framework are transformed. Through the resolution of contradictions between the grand narratives about the West and the East, ancient China seems to fit neatly into Gille's global framework.

After this reconfiguration, it is difficult for readers to make out the original narrative that has been converted. For example, in the chapter concerning the Arab world, Gille admits that it "held a strategic position between the western and Asiatic worlds, thus permitting vital technical exchanges to take place, such as the importation into the West of certain types of steel from India, along with paper and the compass, to give but a few examples" (Gille, 1986a, p. 426). The mentioning here of paper and the compass would seem to confirm the notion of unidirectional technology transfer from the East to the West. Gille, however, treats them as evidence supporting the opinion of technological exchange. In order to induce readers to neglect the notion of unidirectional technology transfer, he immediately adds that those important technologies are "but a few examples". His complement implies that the technological objects are chosen randomly and that significant cases of importing into the East from the West can also be given. When readers overlook unintentionally the question whether those examples are appropriate and turn their attention to the technological exchange, the notion of unidirectional technology transfer from the Far East to the West once again seems to be successfully spirited away from the text. 
Yao Dazhi

Per Högselius

The transformation nearly renders the conventional narrative of China's technology invisible, and the arrangement of the material in The History of Techniques illustrates a certain pattern of Chinese development that denies the splendid technological civilization of China.

\section{Concluding remarks}

It has not been the purpose of this paper to determine whether Gille was right or wrong; rather, we are interested in his approach to resolving the contradictions between Western- and Eastern-centric narratives. By scrutinizing Gille's discussion of Chinese technology and its role in the global technical evolution, we have tried to reconstruct his research strategy and discern the key elements on which his overall argument about China and the West in the history of technology are based.

Gille differs from earlier Western-centric historians by actively engaging in a debate with contemporary Eastern-centric historians of science and technology, notably Needham. He tries to absorb different perspectives into his framework and relieve the tension between seemingly contradictory narratives. The result is remarkably consistent, although Gille at times also seems to contradict himself. For example, at one point he admits that "gunpowder" actually might have been imported from the Far East rather than being of local European origin (Gille, 1986a, p. 497), and points to the Chinese "mixture" of saltpeter, sulfur, and charcoal dust as a significant military invention. Remnants of the conventional China-centric narrative are thus to a certain extent still visible in Gille's account.

The treatment of China in The History of Techniques explicitly criticizes or rejects the arguments of many other historians of Chinese technology. It is interesting to see, however, that more and more historians of Chinese science and technology have become interested in the transnational and global approach that Gille sought to foster. They have studied in depth phenomena such as cross-cultural transfer of technology and knowledge and have developed comparative approaches. In this way, the relationship between Western- and Eastern-centered narratives developed in interesting directions during the past few decades. Through our reconstruction of Gille's transformation of the narrative of the history of Chinese technology, we encourage other historians and philosophers of technology to pay 
attention to The History of Techniques — and other "classical" works in the history of technology — when following up on this promising trend.

\section{Acknowledgements}

The research underlying this article was supported by the research priority program of the Institute for the History of Natural Sciences, CAS, Grant number Y45001204G. Completion of the final version of the paper was supported by the Chinese Academy of Sciences Fellowships for Young International Scientists, Grant number 2013Y2JA0004.

\section{References}

Bray, F. (1998), 'Technics and Civilization in Late Imperial China: An Essay in the Cultural History of Technology,' Osiris, vol. 13, pp. 11-33. http://dx.doi.org/10.1086/649278

- (2002), 'Towards a Critical History of Non-Western Technology,' in T. Brook \& G. Blue (eds.) China and Historical Capitalism: Genealogies of Sinological Knowledge, Cambridge: Cambridge University Press, pp. 158-209.

_ (2009), 'Chinese Technology', in J. K. B. Olsen, S. A. Pedersen \& V. F. Hendricks (eds.) A Companion to the Philosophy of Technology, West Sussex: Blackwell Publishing, Ltd., pp. 28-31. http://dx.doi.org/10.1002/9781444310795.ch4

Fox, R., ed. (1998), Technological Change: Methods and Themes in the History of Technology, Amsterdam: Harwood Academic Publishers.

Gille, B. (1956), 'Machines,' in C. Shinger, E. J. Holmyard, A. R. Hall \& T. I. Williams (eds.) A History of Technology, vol. II, Oxford: Oxford University Press, pp. 629-658. - (1962), 'The Medieval Age of the West (Fifth Century to 1350),' in M. Daumas (ed.) A History of Technology and Invention: The Origins of Technological Civilization, transl. by E. B. Hennessy, New York: Crown Publishers Inc., vol. 1, pp. 421-476. ['Le Moyen Age en Occident (Ve siècle-1350),' in M. Daumas (ed.) Histoire générale des techniques: Des origines au XVe siècle, Paris: Presses universitaires de France, pp. 427-598.]

— (1978), Histoire des techniques, Paris: Gallimard.

- (1986a), The History of the Techniques: Techniques and Civilizations, vol. I, transl. by P. Southgate and T. Williamson, New York: Gordon and Breach Science Publishers. (1986b), The History of the Techniques: Techniques and Sciences, vol. II, transl. by J. Brainch and K. Butler, etc., New York: Gordon and Breach Science Publishers. 
Hilaire-Pérez, L. \& Verna, C. (2006), 'Dissemination of Technical Knowledge in the Middle Ages and the Early Modern Era: New Approaches and Methodological Issues,' Technology and Culture, vol. 46 (July), pp. 536-565. http://dx.doi.org/ 10.1353/tech.2006.0179

Hughes, T. P. (1983), Networks of Power: Electrification in Western Society, 1880-1930, Baltimore: John Hopkins University Press.

- (2012), The Evolution of Large Technological Systems, in W. E. Bijker, T. P. Hughes \& T. Pinch (eds.) The Social Construction of Technological Systems: New Directions in the Sociology and History of Technology, Cambridge, MA: The M.I.T. Press, pp. 51-82. PMCid:PMC3565660

Jacomy, B. (1990), Une Histoire des Techniques, Paris: Seuil.

Needham, J. (1945), Chinese Science, London: Pilot Press, Ltd. (1981), Science in Traditional China: A Comparative Perspective, Cambridge, MA: Harvard University Press.

(2005), 'Introduction,' in R. K. G. Temple, The Genius of China: 3,000 years of science, discovery, and invention, London: Prion.

Pan, J. (2002), Four Great Inventions of Ancient China-Origin, Dissemination and Influence in the World, Hefei: China University of Science and Technology Press. [ 潘吉星 (2002), 中国古代四大发明一一源流、外传及世界影响，合肥：中 国科学技术大学出版社. ]

Picon, A. (1998), Toward a History of Technological Thought, in R. Fox (ed.) Technological Change: Methods and Themes in the History of Technology, Amsterdam: Harwood Academic Publishers, pp. 37-50.

Wu, G. (2009), Lectures on the Philosophy of Technology, Beijing: China Renmin University Press. [吴国盛 (2009), 技术哲学讲演录, 北京: 人民大学出版社.]

Zhang, B. (2004), The Soviet Union Technology Transfer to China (1949-1966), Jinan: Shandong Education Press. [张柏春 (2004), 苏联技术向中国的转移(19491966), 济南: 山东教育出版社.]

Yao Dazhi is associate professor at the Institute for the History of Natural Sciences, Chinese Academy of Sciences, Beijing. He holds a PHD in philosophy of science and technology (2010). His areas of interest include philosophy of technology, historiography of science and technology, French history of science and technology.

Per Högselius is associate professor at the Division of History of Science, Technology and Environment at KTH Royal Institute of Technology, Stockholm. He holds a PHD in innovation studies (2005) and a docent (habilitation) degree in history of science and technology. His research focuses on transnational history of technology, with a special emphasis on East-West relations. 